\title{
La producción textil en al-Andalus: origen y desarrollo ${ }^{1}$
}

\author{
Laura RodRíguez PeInAdo \\ Dpto. Historia del Arte I (Medieval) \\ Universidad Complutense de Madrid \\ lrpeinado@ghis.ucm.es
}

A la producción textil andalusí se le han dedicado numerosas publicaciones en las que se aborda su estudio desde diferentes aspectos, ya sean históricos, económicos o artísticos. En este estudio pretendemos llamar la atención sobre ciertas singularidades propias del arte textil andalusí desde el inicio de su industria en el siglo VIII hasta el siglo XI que afectan a su origen y su relación con la producción hispana y mediterránea, y a su caracterización técnica y decorativa. Es un período de gran importancia porque a pesar de que no es el más prolijo en cuanto al número de piezas conservadas, estas permiten conocer el punto de partida y la evolución de su industria, así como las relaciones con las manufacturas contemporáneas, de las que se ha considerado deudora.

A la llegada de los musulmanes a la Península Ibérica existía una tradición manufacturera textil basada, básicamente, en tejidos de sencilla factura elaborados en telares verticales y posiblemente ligada al ámbito privado. La lana y el lino fueron las fibras textiles más utilizadas, siendo destacada su calidad por los escritores latinos, quienes también hacen mención a las sustancias tintóreas, entre las que destacó la obtención de la púrpura. Aunque no tenemos noticias concretas sobre la producción textil peninsular a la llegada de los musulmanes, estos se encontraron con un territorio donde esta actividad no había sido ajena a sus habitantes y al menos durante la época romana había gozado de una organización similar a la de otros territorios del Imperio. Estos precedentes serían fundamentales para el desarrollo de esta industria en el ámbito andalusí, que pronto llegó a ser tan próspera que ocupó a una parte importante de la población en las distintas actividades que formaban parte del proceso, que comenzaba con la obtención de las materias primas y terminaba con la comercialización de los productos manufacturados. Porque no se puede entender el auge de esta manufactura, basada en una compleja tecnología, quizás con las instalaciones más sofisticadas del entramado productivo de la sociedad andalusí, sin contar con una infraestructura previa que permitió poner en marcha todo el sistema productivo.

1 Este trabajo se incluye en el marco del Proyecto de Investigación del Ministerio de Ciencia e Innovación HAR2008-04161 "Caracterización de las producciones textiles de la Tardoantigüedad y la Edad Media temprana: tejidos coptos, sasánidas, bizantinos e hispanomusulmanes en las colecciones públicas españolas”. 
La tradición textil en la Península Ibérica se remonta a las primeras etapas de su historia, como evidencian los restos arqueológicos y las fuentes escritas. Autores como Estrabón (Geografia), Plinio (Natural Historia) e Isidoro de Sevilla (Etimologías), entre otros, informan sobre las actividades textiles de sus pobladores.

Se conservan diferentes fragmentos procedentes de yacimientos prehistóricos, argáricos, ibéricos y de enterramientos romanos que nos permiten conocer la tecnología y la técnica de tejeduría ${ }^{2}$. Las fibras textiles más utilizadas fueron la lana y el lino, pero también se utilizaron otras como el esparto. En cuanto a las técnicas de tejido, predominan los tejidos $\operatorname{lisos}^{3}$ y los asargados ${ }^{4}$ que se realizarían en telares verticales ${ }^{5}$.

En época romana, la industria textil y oficios afines ocuparon a un importante número de población y generaron un importante comercio, lo que supuso la profesionalización de los trabajos textiles ${ }^{6}$. Las materias primas más utilizadas fueron la lana y el lino, tanto para confeccionar tejidos ordinarios como telas finas, pero también se utilizaron el cáñamo y el esparto. El algodón, originario de la India, pudo trabajarse en Egipto, aunque son escasos los tejidos donde se ha detectado su presencia y de difícil datación; y la seda fue muy demandada en Roma y comercializada en el Imperio por los persas, que actuaban de intermediarios ${ }^{7}$.

En Hispania no se han localizado tejidos de seda ni de algodón de época romana. La fibra más utilizada fue la lana. La de la Bética se exportó a otros centros textiles del Imperio. Estrabón (3.2.6) y Plinio (8.191) citan la calidad de los tejidos de fina lana de Salacia (Alcácer do Sal, Portugal). El lino se cultivó en toda la periferia peninsular. Estrabón describe a los habitantes de Emporion como muy diestros en la fabricación de tejidos de lino (3.4.9) y menciona el cultivo de la planta en Lusitania (3.3.6). El lino de Tarraco y de Saetabis (Xàtiva) es citado por Plinio (19.9-10). En Carthago Nova se cultivaron grandes cantidades de esparto que además de destinarse a la exportación se utilizaron para el calzado, espuertas para transportar mineral, cestas, cuerdas, redes, etc. (Estrabón, 3.4.9; Plinio, 19.26-30).

2 C. ALFARO GINER, Tejido y cestería en la Península Ibérica. Historia de su técnica e industrias desde la Prehistoria hasta la romanización, Madrid, 1984. En esta obra la autora da cumplida cuenta de los restos conservados hasta la época romana estudiándolos en su ámbito cultural y caracterizándolos técnicamente.

3 Es el tejido que se conoce como tafetán y consiste en el paso de un hilo de trama por encima de los hilos pares de la urdimbre en una pasada y por encima de sus hilos impares en la siguiente.

4 Este ligamento sigue básicamente el tafetán pero con la diferencia que en las pasadas sucesivas de tramas que conforman la tela, el sistema de entramado se va desplazando un lugar hacia la derecha o la izquierda, resultando un tejido con estructura en diagonal.

5 Telares formados por dos pies derechos que soportan un cilindro donde se disponen las urdimbres en perpendicular al suelo. Estos telares pueden ser de dos tipos: telar vertical de marco, conocido ya en el Antiguo Egipto, en el que además del travesaño superior, hay otro inferior con el que se tensan los hilos de la urdimbre y donde se va enrollando el tejido ya realizado. Telar vertical de pesas, donde los hilos de la urdimbre sujetos en el cilindro superior se agrupan con pesas de piedra que sirven para tensarlos; en estos telares el tejido se fabrica de arriba abajo. Para una explicación muy gráfica de estos artefactos, véase C. ALFARO GINER, El tejido en época romana, Madrid, 1997, pp. 41-54.

6 Ídem, "Nuevas aportaciones para la historia de la evolución tecnológica en el Bajo Imperio", Antigüedad y Cristianismo, VIII (1991), pp. 409-422.

7 J. THORLEY, "The Silk Trade between China and the Roman Empire at Its Height, 'Circa' A.D. 90-130", Greece \& Rome, 18 (1) (1971), pp. 71-80. La primera seda china que llegó a Roma se usó en el baldaquino de la procesión triunfal de Julio César en el año 46 a.C. 
Los tejidos estaban teñidos con una variada gama cromática obtenida a partir de tinturas de origen animal y origen vegetal ${ }^{8}$.

Los azules se obtenían a partir del pastel (Isatis tinctoria) y el índigo (Indigofera tinctoria). El pastel se recolectaba en todo el mundo mediterráneo y a menudo se utilizó como una falsificación del índigo, originario de la India, del que se obtenía un color más intenso y permanente y además no necesitaba de mordiente para su fijación ${ }^{9}$. En la Península Ibérica ya se producía pastel en época romana, localizándose en torno a Toledo una importante zona de producción y exportación.

Los tintes rojos se obtenían de la granza (Rubia tinctorum), planta originaria de Oriente y que se acomoda a todo tipo de climas. Crecía de manera espontánea pero pronto se adaptó a cultivos que se extendieron a todo el Imperio.

Para los tintes amarillos se usaba la gualda (Reseda luteola) en sus variantes silvestre y cultivada. Plinio (33. 87) destaca sus cualidades para teñir la lana y la seda. Usada con mordientes se podían conseguir otras tonalidades, como los verdes.

Entre los tintes de origen animal el más apreciado fue la púrpura, obtenida a partir de los muricidae ${ }^{10}$. Fue el tinte más cotizado en la Antigüedad. Aunque su origen parece estar en las costas de Siria y Palestina, donde fue explotado por los fenicios, las explotaciones se extendieron con rapidez por las costas mediterráneas, destacando las hispanas por su volumen de producción a tenor de los depósitos arqueológicos ${ }^{11}$. La púrpura al servicio de la ideología del poder se perpetuó en el imperio bizantino, pero los murex se mencionan raras veces en las fuentes islámicas ${ }^{12}$.

También de origen animal es el quermes o kermes que proporciona rojos de gran calidad $^{13}$. Para algunos autores como Dioscórides, el procedente de Hispania era el de peor calidad, mientras para Plinio ocupaba el segundo lugar y permitía que gente con escasos recursos pudiera recolectarlo y entregarlo a modo de impuestos ${ }^{14}$.

Poco podemos decir en cuanto a las técnicas textiles de los ejemplares hispanos, porque los que han llegado hasta nosotros son tejidos lisos, seguramente ejecutados

8 La obra de D. CARDON, Le monde des teintures naturelles, París, 2003, es fundamental para conocer los tintes naturales y las diferentes técnicas de tintura. Para el proceso de teñido en el ámbito romano véase J. JUAN-TRESSERRAS, "El uso de plantas para el lavado y el teñido en época romana. Análisis de residuos de la fullonica y la tinctoria de Barcino", Complutum, 11 (2000), pp. 245-252.

9 Los mordientes son sales metálicas como el alumbre, ácidos como el tanino, y sustancias orgánicas que fijan los colores en las fibras. Por su naturaleza son difíciles de detectar en los tejidos antiguos. D. CARDON, op. cit., 2003, pp. 13-14.

10 Ibídem, pp. 422-425; P. FERNÁNDEZ URILEL, Púrpura. Del mercado al poder, Madrid, 2010, p. 75.

11 C. ALFARO GINER y E. TÉBAR MEGIAS, "Aspectos históricos, económicos y técnicos de la producción de púrpura en la Ibiza romana”, Purpurae Vestes I. Textiles y tintes del Mediterráneo en época romana, Valencia, 2004, pp. 195-210; C. ALFARO y B. COSTA, "Methodological Aspects of Purple Dye Production on Ibiza: the New Site of Cala Olivera", Purpurae Vestes II. Vestidos, textiles y tintes, Valencia, 2008, pp. 195-208; D. BERNAL CASASOLA, A. M. SÁEZ ROMERO y M. BUSTAMANTE ÁLVAREZ, "Púrpura y pesca en el Gadir tardopúnico. La fosa-conchero de desechos haliéuticos de la C/ Luis Milena (San Fernando, Cádiz)", Purpurae Vestes III. Textiles y tintes en la ciudad antigua, Valencia, 2011, pp. 157-180.

12 M. LOMBARD, Les textiles dans le monde musulman. VII ${ }^{e}$-XII siècle, París, 1978, p. 118.

13 El quermes se obtiene a partir de un tipo de insectos denominados cóccidos cuyas hembras parasitan la familia arbórea de los quercus (encinas y robles), que al clavar el aguijón en la corteza producen un tinte muy consistente. D. CARDON, op. cit., 2003, pp. 476-508.

14 C. ALFARO GINER, op. cit., 1984, p. 204. 
en los tradicionales telares verticales; probablemente se utilizaría la técnica de tapicería con tramas de lana coloreada para los motivos ornamentales, porque fue la técnica más extendida en los diferentes centros textiles de la Antigüedad Tardía, conocida bien a partir de los tejidos exhumados en los enterramientos del Valle del Nilo ${ }^{15}$.

Las referencias epigráficas ${ }^{16}$ permiten construir cómo eran los distintos procesos de producción en Hispania, quiénes intervenían en ellos y cuál era su grado de especialización ${ }^{17}$. Aunque los tejidos para el uso familiar se hicieran en el ámbito doméstico, la industria textil era más compleja y generaba un importante volumen de negocio.

Nada conocemos de la actividad textil en la Península durante el reino visigodo. Es de suponer que se mantendrían las mismas estructuras de producción que en el período anterior, con predominio de las domésticas, fabricando tejidos con los materiales y técnicas tradicionales ${ }^{18}$. Pero aunque la lana continuó siendo el material más utilizado, los reyes y la alta nobleza gustaron de tejidos de seda - pannos greciscos- seguramente importados de Bizancio a través de comerciantes establecidos en los territorios de la Bética, bajo dominio bizantino, porque aunque se ha llegado a sugerir el establecimiento de un gineceo en Cartagena, no hay indicios que ayuden a corroborar esta hipótesis ${ }^{19}$. No se han conservado tejidos lujosos de este período, pero se han podido identificar hilos metálicos en los ajuares funerarios de El Carpio del Tajo (Toledo) y Turuñuelo (Medellín), que dan idea de la importancia del textil en la época como símbolo de estatus social ${ }^{20}$. También es evidente la influencia oriental en la decoración relivaria cuyos modelos, en gran medida, procederían del repertorio textil e incluso, por qué no, rememorarían en piedra las preciadas telas que ennoblecerían los escenarios en ocasiones muy especiales ${ }^{21}$. La importancia del arte textil en el reino visigodo merece un estudio que aún no se ha realizado, porque parece evidente que parejo al deseo de emular el boato bizantino y oriental estaría el gusto y la necesidad de los altos estamentos sociales de cubrirse con bellos y ricos tejidos y de revestir con preciosas telas los escenarios del poder, como se desprende a partir de los textos de la época.

15 L. RODRÍGUEZ PEINADO, Los tejidos coptos en las colecciones españolas: las colecciones madrileñas, Madrid, 2001.

16 H. GIMENO, Artesanos y técnicos en la epigrafia de Hispania, Barcelona, 1988.

17 J. F. RODRÍGUEZ NEILA et alii, El trabajo en la Hispania romana, Madrid, 1999, pp. 84-89.

18 E. GUTIÉRREZ CUENCA y J. A. HIERRO GÁRATE, "Instrumentos relacionados con la actividad textil de época tardoantigua y altomedieval en Cantabria", Munibe, 61 (2010), pp. 261-288. Aquí se dan a conocer artefactos textiles considerados de época visigoda. En la necrópolis visigoda de Castiltierra (Segovia), aparecieron algunos fragmentos de tejido de pequeño tamaño aunque a partir de ellos no se puede caracterizar la producción de este período.

19 L. SERRANO-PIEDECASAS FERNÁNDEZ, "Elementos para una historia de la manufactura textil andalusí (siglos IX-XII)", Studia Historica. Historia Medieval, IV-2 (1986), p. 208.

20 Ibídem, pp. 206-209. Aporta notas interesantes sobre los indicios de lo que pudo ser la industria textil en el período visigodo.

21 Véase para un repertorio de relieves donde se puede apreciar la influencia de los textiles J. M. HOPPE, "Le corpus de la sculpture visigothique. Libre parcours et essai d'interprétation", L. CABALLERO y P. MATEOS (eds.), Visigodos y Omeyas. Un debate entre la Antigüedad Tardía y la Alta Edad Media, Anejos de AEspA XXIII, 2000, pp. 307-355. 
Con todo, la llegada de los musulmanes supuso una eclosión del arte textil en los territorios de al-Andalus basado en las materias primas tradicionales y, fundamentalmente, en la introducción de la sericultura y la primacía de la seda como material textil, que posibilitó la organización de una industria de lujo basada en una nueva tecnología capaz de abastecer de productos no solo al mercado andalusí, porque su calidad favoreció que se exportasen tanto a los territorios cristianos del norte, como al resto de los enclaves del mundo islámico.

Los tejidos constituyeron una fuente generadora de riqueza en la sociedad islámica que favorecieron los intercambios comerciales y políticos ${ }^{22}$. Su manufactura ocupó el primer lugar en la actividad industrial del mundo musulmán, llegándose a documentar poblaciones enteras dedicadas a los distintos procesos que generaba esta industria, caracterizada por su gran especialización y la división del trabajo sometido a controles de calidad indispensables para la comercialización de sus productos, cuya estandarización era marchamo de calidad y es uno de los elementos que puede permitir establecer clasificaciones ${ }^{23}$.

Las cualidades de la lana de la Bética fueron ponderadas por los autores islámicos como ya lo habían sido por los romanos ${ }^{24}$. Mencionan a Valencia como el gran mercado de la lana desde donde se distribuía a todo el Mediterráneo. La producción de lana estuvo unida a la creación de centros textiles como Valencia, Bocairent, Chinchilla y Cuenca. Al-Idrīsī dice de los tejidos de Bocairent (Valencia) que son "suaves y blancos como el papel" y alaba, asimismo, las alfombras de Chinchilla (Albacete) y Cuenca ${ }^{25}$.

Las manufacturas de tejidos de lana fueron herederas de las tradiciones textiles de la Antigüedad Tardía. Ibn Hawqal alaba su excelencia y variedad ${ }^{26}$. De hecho, la lana fue la fibra más utilizada, aunque no se hayan conservado tejidos manufacturados con este material. Hay que destacar la mención a las alfombras, cuya singular técnica consiste en ir atando sucesivamente un cabo a las urdimbres del tejido base que al cortarse producen la característica superficie pilosa y mullida. Pero desconocemos el tipo de nudo con que se confeccionarían ${ }^{27}$.

22 M. LOMBARD, op. cit., 1978, definió a la civilización islámica como la civilización del textil. Hay que señalar que los textiles fueron una de las mercancías más susceptibles para las transacciones comerciales.

23 S. SALADRIGAS CHENG, "Los tejidos en Al-Andalus: siglos IX-XVI. Aproximación técnica", España y Portugal en las rutas de la seda. Diez siglos de producción y comercio entre Oriente y Occidente, Barcelona, 1996, p. 82.

24 M. LOMBARD, op. cit., 1978, pp. 25-26.

25 Ibídem, citado en p. 28.

26 J. VALLVÉ, "La industria en Al-Andalus", Al-Qantara, I, 1-2 (1980), p. 225. Los tejidos de lana se nombraban por la calidad del material y su factura.

27 Véase C. PARTEARROYO LACABA, “Alfombras españolas", Textil e indumentaria: materias, técnicas y evolución, Madrid, 2003. No se puede descartar que los anudados de las alfombras derivasen de tejidos con tramas suplementarias que sujetas a una varilla formaban bucles, técnica de posible origen oriental que se ha puesto en relación con el nudo shena, muy utilizada entre los tejedores del Valle del Nilo, que empleaban los bucles cortos por el anverso del tejido para formar la decoración y bucles largos de lino, bien bordeando la decoración de tapicería, o en el reverso, con la finalidad de proporcionar abrigo (L. RODRÍGUEZ PEINADO, op. cit., 2001, pp. 159-160). Por otra parte, no hay que descartar que se tejieran con nudo español, caracterizado por anudar en cada pasada un solo hilo de urdimbre dejando libre el contiguo, para pasar a anudar 
El lino peninsular fue tan apreciado por su calidad como el lino egipcio. Los autores árabes citan, entre otros, el de Valencia, Málaga, Orihuela, Granada, Lérida y Mallorca. Ibn Hawqal cuenta que los tejedores andalusíes eran muy habilidosos en su manufactura. Se mencionan por su calidad los finos tafetanes de Valencia, que teñidos con azafrán o quermes se exportaban a todo Occidente; los velos producidos en Almería; y las telas de Zaragoza ${ }^{28}$. Con lino se hacían cendales ${ }^{29}$, turbantes y otras prendas de vestir.

Entre los tejidos de cáñamo se mencionan los de Almería, Zaragoza, Bocairent y Jódar $^{30}$.

El algodón, originario de la India, se conocía en el mundo mediterráneo a través de su comercialización en bruto o manufacturado. Su explotación se extendió por la cuenca del Mediterráneo en la época musulmana, dándose en al-Andalus las condiciones favorables para su implantación ${ }^{31}$, donde ocupó terrenos previamente dedicados al cultivo del lino, fundamentalmente en el Aljarafe sevillano ${ }^{32}$. La producción de algodón peninsular fue tan abundante que una parte importante se dedicó a la exportación ${ }^{33}$.

Pero la fibra textil por excelencia de la industria andalusí fue la seda ${ }^{34}$. Procedente de China, su uso y cultivo se fue extendiendo de forma progresiva, primero asociada a un mercado de lujo en madejas y tejidos, y posteriormente el secreto de la sericultura a través de la Ruta de la Seda, siempre vinculada a leyendas fabulosas ${ }^{35}$. La expansión del Islam fue un período dinámico para la extensión de la sericultura que comportó, asimismo, una revolución de la economía de los tejidos de lujo al multi-

los que se habían dejado libres en la pasada siguiente; pero los ejemplares más antiguos que se conservan con este tipo de nudo proceden de Fustat y están fechados en los siglos XII y XIII.

28 Véase para lo relativo a esta fibra M. LOMBARD, op. cit., 1978, pp. 51-53.

29 En R. M. DÁVILA CORONA, M. DURAN PUJOL y M. GARCÍA FERNÁNDEZ, Diccionario histórico de telas y tejidos, Salamanca, 2004, pp. 59-60 se define como tela ligera, sutil y transparente.

30 L. BOLENS, "The Use of Plants for Dyeing and Clothing. Cotton and Woad in al-Andalus: a Thriving Agricultural Sector $\left(5^{\text {th }} / 11^{\text {th }}-7^{\text {th }} / 13^{\text {th }}\right.$ Centuries)", S.K. JAYYUSI (ed.), The Legacy of Muslim Spain, Leiden, 1992, p. 1008.

31 En el Calendario de Córdoba (961) se recoge su ciclo de producción y es citada esta fibra en una donación de casullas a León en el año 951. L. SERRANO-PIEDECASAS FERNÁNDEZ, op. cit., 1986, pp. 210 y 219.

32 L. BOLENS, op. cit., 1992, pp. 1004-1008.

33 O. R. CONSTABLE, Trade and Traders in Muslim Spain: The Commercial Realignment of the Iberian Peninsula, 900-1500, Cambridge, 1994, pp. 142-143.

34 E. MORRAL I ROMEU y A. SEGURA I MAS, La seda en España. Leyenda, poder y realidad, Barcelona, 1991, pp. 11-36 describen el proceso de la sericultura. La seda es una fibra procedente de la oruga bombyx mori, que se alimenta de la hoja de la morera o el moral y en su fase de adulto se encierra en un capullo donde se produce su metamorfosis. Es en este momento cuando segrega el filamento de seda que puede alcanzar una longitud de 500 a $1200 \mathrm{~m}$. Formada por dos proteínas, fibroína y sericina, sus propiedades la convierten en única por su solidez, resistencia y brillo.

35 Se atribuye el origen mítico de la sericultura a la emperatriz Silingshi, esposa del también mítico Emperador Amarillo, Huangdi ( $c$ a. 3000 a.C.). Los hallazgos arqueológicos revelan el origen de la sericultura incluso antes de estas fechas en las civilizaciones neolíticas instaladas en las inmediaciones del río Amarillo, Hoang-he. E. LEWIS, La novelesca historia de los tejidos, Madrid, 1959, pp. 34-39; M. LOMBARD, op. cit., 1978, pp. 81-104; E. MORRAL I ROMEU y A. SEGURA I MAS, op. cit., 1991, pp. 43-51. 
plicarse los centros de producción donde se fueron incorporando y originando las nuevas tecnologías y los nuevos códigos ornamentales.

La cría del gusano de seda y de la morera se introdujeron en al-Andalus hacia el año 740 coincidiendo con las migraciones de tribus sirias en la Vega de Granada, Jaén, Niebla y el Aljarafe, zonas donde las condiciones climáticas favorecieron su cultivo en alquerías ${ }^{36}$. En el Calendario de Córdoba (961) se enumera el ciclo anual del trabajo que abarcaba su proceso de producción, la legislación que regulaba todos los aspectos relacionados con la cría de los gusanos, la proporción de hojas de morera para su alimentación y las transacciones que se realizaban con el preciado material ${ }^{37}$.

Al-Andalus fue el primer territorio europeo donde se introdujo la sericultura ${ }^{38} \mathrm{y}$, con tal prosperidad, que los tejidos de seda andalusíes fueron apreciados desde fechas muy tempranas tanto en Oriente como en Occidente ${ }^{39}$.

A menudo la seda iba asociada al empleo de hilos metálicos ${ }^{40}$, lo que en el caso de los tejidos andalusíes se constata desde las piezas con cronología más temprana singularizando sus producciones.

Las fuentes documentales mencionan una fibra textil cuyo origen no queda claro, la lana marina o byssus ${ }^{41}$. Parece que se trata de los filamentos de un molusco conocido como pluma de mar o pennatula con cuyas fibras, similares a la seda hilada -también se denomina seda marina-, se tejían piezas de color natural que se tornaban iridiscentes con los efectos de la luz ${ }^{42}$.

El estudio de los colorantes es determinante para conocer la procedencia de los tejidos ${ }^{43}$. Al-Andalus desarrolló una importante industria tintórea con tintoreros es-

36 M. LOMBARD, op. cit., 1978, pp. 95-96.

37 M. V. LAGARDERE, "Mûrier et cultura de la soie en Andalus au Moyen Age (X ${ }^{\mathrm{e}}-\mathrm{XIV}$ e siècles)", Mélanges de la Casa de Velázquez, 26-1 (1990), pp. 99-105.

38 La sericultura se introdujo en Sicilia en los siglos IX o X y hasta la segunda mitad del siglo XII no se implantó en Lucca, G. NAVARRO ESPINACH, "El arte de la seda en el Mediterráneo medieval", En la España medieval, 27 (2004), p. 12.

39 En el Liber Pontificalis aparecen citados los primeros textiles andalusíes en el pontificado de Gregorio IV (827-844). L. SERRANO-PIEDECASAS FERNÁNDEZ, op. cit., 1986, p. 210.

40 Si desde la Antigüedad los hilos metálicos se formaban con una fina lámina de oro o plata entorchada a un hilo, a partir del siglo X aproximadamente se impone el denominado oropel u oro de Chipre, constituido por un alma que normalmente es un filamento de seda a la que se enrolla una fina piel que lleva adherida una lámina metálica de oro, plata o latón: A. CABRERA LAFUENTE, "Los tejidos como patrimonio: investigación y exposición”, Bienes Culturales. Revista del Instituto del Patrimonio Histórico Español, 5 (2005), pp. 8-9.

41 F. MAEDER, A. HÄNGGI y D. WUNDERLIN (eds.), Bisso marino, fili d'oro dal fondo del mare (Muschelseide, Goldene Fäden vom Meeresgrund), Basilea-Milán 2004.

42 J. VALLVÉ, op. cit., 1980, pp. 228-229, menciona veintiún mantos de lana marina obsequiados por Almanzor a los condes cristianos que habían colaborado en la campaña de Compostela del año 997 . Los egipcios llamaban bissus a los tejidos de lino de textura muy fina y parece ser que esta terminología pasó al mundo islámico, pudiéndose considerar tejidos de lino fino los bisso que se mencionan en la documentación de los territorios cristianos, L. SERRANO-PIEDECASAS FERNÁNDEZ, op. cit., 1986, p. 217. No se ha documentado hasta el momento ningún tejido de este tipo, por lo que es difícil establecer sus características, L. BOLENS, op. cit., 1992, pp. 1009-1010. Los príncipes omeyas se reservaban el uso por su valor y exclusividad, C. PARTEARROYO LACABA, "Las telas de los santos, de los reyes y de los califas: los tejidos en A1Andalus (ss. X-XIII), Santiago - Al-Andalus: diálogos artísticos para un milenio, Santiago de Compostela, 1997 , p. 375 , nota 5 .

43 A. CABRERA LAFUENTE, "Caracterización de las producciones textiles en Al-Andalus (siglos IX al XIV): estudio sobre tintes”, M. MARÍN (ed.), Tejer y vestir, de la Antigüedad al Islam, Madrid, 2001, pp. 395-417. 
pecializados en el uso de colorantes específicos. Está documentado el cultivo de una gran cantidad de plantas ${ }^{44}$ destinadas a proveer de materias primas a una industria fundamental para el desarrollo de la producción textil, ya que el color constituyó un símbolo de estatus, pero también implicaba un concepto de moda y aportaba un valor añadido a los tejidos destinados al comercio exterior.

El pastel o glasto se cultivaba en torno a Toledo. Parece que no hubo plantaciones de índigo, que se obtenía a través del comercio concentrado en manos de los judíos ${ }^{45}$. Los análisis de tintes llevados a cabo con muestras de tejidos hispanomusulmanes detectan indigotina ${ }^{46}$, presente en ambos colorantes, pero parece evidente que en alAndalus se utilizaron ambas tinturas, ya que las cualidades del índigo le hicieron necesario para teñir los tejidos más suntuosos.

Para la obtención de los rojos, los tintes más utilizados en los tejidos andalusíes fueron la granza y el quermes. El cultivo de la granza se daba en campos o jardines, siendo reputada la de Sidona (Medina Sidonia) ${ }^{47}$. En el Calendario de Córdoba (961) se recoge la normativa sobre su recolección ${ }^{48}$. El quermes se producía en gran cantidad en la Península, pero en especial adquirió fama el del área de Sevilla. Parte de su recolección era requisada para el tiraz, como describe el Calendario de Córdoba ${ }^{49}$.

Otros tintes detectados en los tejidos para la obtención del rojo fueron el liquen orceilla, la madera de brasil (Caesalpina sappan), el tinte laca y la cochinilla armenia, todos ellos procedentes de la importación ${ }^{50}$. A pesar de que los mencionan las fuentes, no se han detectado en los tejidos analizados alheña y cártamo ${ }^{51}$.

Las dos sustancias utilizadas para la obtención de los amarillos fueron la gualda y el azafrán. Ambos han sido detectados en los análisis de colorantes realizados, aunque en mayor proporción el primero ${ }^{52}$. El cultivo del azafrán (Crocus sativus) se introdujo en la Península en época musulmana; ya en el siglo IX se convirtió en uno de los principales productos de exportación y al-Andalus en uno de los países productores y exportadores más importantes ${ }^{53}$. Si se utiliza solo, se caracteriza por su tono dorado; con mordientes de aluminio y estaño, los tonos son anaranjado y amarillo respectivamente. Es posible que se usase en menor medida que la gualda por reservarse para piezas de mayor costo y factura más refinada.

44 M. LOMBARD, op. cit., 1978, pp. 117-145, incluye muchas plantas cuya presencia no se ha detectado en los análisis de colorantes llevados a cabo, por lo que en este estudio nos centraremos en estas últimas.

45 Ibidem, p. 139; J. BALFOUR-PAUL, Indigo in the Arab World, Londres, 1997, pp. 14-28.

46 Tanto en los análisis que hemos llevado a cabo en el marco del proyecto (inéditos) como en los llevados a cabo en el Instituto del Patrimonio Cultural de España. M. D. GAYO GARCÍA y A. ARTEAGA, "Análisis de colorantes de un grupo de tejidos hispanomusulmanes", Bienes Culturales. Revista del Instituto del Patrimonio Histórico Español, 5 (2005), pp. 134, 142-143.

47 M. LOMBARD, op. cit., 1978, p. 125.

48 R. DOZY (ed.). Le calendrier de Cordoue, Leiden, 1961, pp. 144-145.

49 LOMBARD, op. cit., 1978, p. 123.

50 M. D. GAYO GARCÍA y A. ARTEAGA, op. cit., 2005, p. 134.

51 M. LOMBARD, op. cit., 1978, pp. 126-129.

52 M. D. GAYO GARCÍA y A. ARTEAGA, op. cit., 2005, p. 134. En los análisis que hemos realizado en el marco del proyecto, todos los amarillos se obtienen con gualda.

53 LOMBARD, op. cit., 1978, p. 133; E. GARCÍA, "Las plantas textiles y tintóreas en al-Andalus", M. MARÍN (ed.), Tejer y vestir, de la Antigüedad al Islam, Madrid, 2001, pp. 434-436. 
En la franja del Pirineo y en el almaizar de Hisam II los amarillos se obtienen a partir de bayas persas (Rhamnus tinctorius), también cultivadas, al parecer, en la Península ${ }^{54}$.

En las muestras analizadas también se han detectado taninos, tanto mordientes para modificar el color, como para obtener los pardos y negros. Los taninos son sustancias procedentes de distintas especies del reino vegetal y presentes sobre todo en sus cortezas y agallas. Los descubiertos en los tejidos andalusíes son el zumaque (Rhus coriaria), las agallas de nuez y roble (Cypis gallae tinctorae y Quercus infectoria), y el té negro (Camellia sinensis) ${ }^{55}$.

El color verde se obtenía, normalmente, a partir de una mezcla de colorantes amarillo y azul ${ }^{56}$.

Las técnicas más habituales en los primeros siglos de producción textil andalusí, a la luz de los tejidos conservados, fueron el tafetán y los samitos. Los primeros se podían decorar con franjas en técnica de tapiz ${ }^{57}$; y si al principio pudieron ejecutarse en telares verticales, estos pronto se sustituirían por telares horizontales de pedales que permitían mayor rapidez en la ejecución ${ }^{58}$. Los samitos, al ser tejidos labrados, se confeccionaban en telares especiales denominados de tiro o de lazos que permiten repetir los diseños ${ }^{59}$. Hay que tener en cuenta que la clasificación técnica puede ser

54 M. D. GAYO GARCÍA y A. ARTEAGA, op. cit., 2005, pp. 134 y 141.

55 Ibídem, pp. 134 y 143-144. En las muestras analizadas en el marco del proyecto se ha detectado la presencia de taninos como colorantes y como mordientes.

56 En las muestras de verde analizadas en el proyecto se ha detectado mayoritariamente mezcla de índigo y gualda, en menos casos se unen a estos colorantes taninos, y en otros casos solo se observa presencia de índigo, mientras en las muestras estudiadas por A. CABRERA LAFUENTE, op. cit., 2001, p. 411, se detecta en algunos casos solo gualda y en otros gualda o índigo con taninos, lo que nos lleva a pensar que en los casos en los que hay un solo colorante, posiblemente actuaba junto a mordientes que no se han revelado. En las fuentes documentales se cita para la obtención del verde una mezcla de cobre o plomo con vinagre: LOMBARD, op. cit., 1978, p. 143

57 La técnica de tapiz se elabora con ligamento de tafetán y se utiliza para formar los diseños decorativos. Consiste en pasar tramas que ocultan por completo la urdimbre y se limitan a la zona que requiere el dibujo, siendo retomadas en la pasada siguiente. Las tramas se enrollan en canillas que quedan en suspenso cuando no son utilizadas. En el telar horizontal los hilos de la urdimbre se distribuían en unos lizos sujetos a unos pedales accionados por el tejedor, lo que permitía trabajar con más rapidez al poder manejar este con mayor soltura las canillas al no tenerse que ocupar de mover los lizos con las manos.

58 P. BORREGO DÍAZ, “Análisis técnico de ligamentos en los tejidos hispanoárabes", Bienes Culturales. Revista del Instituto del Patrimonio Histórico Español, 5 (2005), p. 76.

59 El samito es un ligamento compuesto por dos urdimbres, una de base y otra suplementaria o de efecto, y al menos dos tramas, de modo que aparecen por el anverso las que conforman la decoración a base de un ligamento de sarga. Véase para su descripción A. MUTHESIUS, "Essential Processes, Looms and Technical Aspects of the Production of Silk Textiles", Dumbarton Oaks Studies, 39 (2002), pp. 147-168; C. VERHECKEN-LAMMENS, A. de MOOR y B. OVERLAET, "Radio-carbon Dated Silk Road Samites in the Collection of Katoen Natie, Antwerp", Iranica Antiqua, XLI (2006), pp. 234-243; A. de MOOR, C. VERHECKEN-LAMNENS y A. VERHECKEN, 3500 Years of Textile Art. The Collection Art in Headquarters, Tielt, 2008, pp. 82-83. Un excelente estudio gráfico de los ligamentos es realizado por P. BORREGO DÍAZ, op. cit., 2005, pp. 75-78. Posiblemente ingeniados en los territorios centrales de la Ruta de la Seda dominada por los sasánidas (226-651 d.C.) fueron apreciados en los territorios del Imperio Romano, conservándose ejemplares desde el siglo III d.C., aunque es entre los siglos V y IX cuando se data el mayor número de piezas: A. de MOOR, C. VERHECKEN-LAMNENS, A. VERHECKEN, op. cit., 2008, pp. 60-62, 128-129, 234- 245 estudian samitos datados por radiocarbono desde el siglo III d.C. Se caracterizan porque repiten un diseño a lo largo de toda la pieza, por eso precisan telares de tiro o de lazos que facilitan su realización. En estos telares 
de gran ayuda para identificar centros textiles, pero la movilidad de la población en el mundo islámico auspició el intercambio de procesos técnicos entre centros muy distantes.

Uno de los aspectos que al parecer caracterizó la producción textil andalusí a diferencia de la producción peninsular anterior fue la utilización de una tecnología más sofisticada que posibilitaba la ejecución de telas labradas. Los hallazgos arqueológicos permiten confirmar la presencia de telares horizontales en yacimientos islámicos por la aparición de algunas piezas empleadas en este tipo de telares denominadas templazos ${ }^{60}$, que permitían formar orillos y ajustar lo más posible la anchura del telar para que el tejido no se deformase. Estos telares de procedencia oriental convertirían con el tiempo a la industria textil andalusí en una de las más importantes del mundo islámico por la calidad de sus tejidos, capaz de competir con los productos iraníes, sirios, egipcios y bizantinos.

Si hacia el año 740 se introdujo la sericultura, podemos pensar que a mediados de la octava centuria ya se habrían formado talleres organizados que permitirían combinar las prácticas más tradicionales con las más especializadas para producir tejidos de seda. Es posible que con 'Abd al-Rahmān I y sus seguidores sirios, entre los que llegaron artesanos cualificados, vinieran tejedores que aportarían el dominio de la alta tecnología, como era el manejo de los telares de tiro con los que fabricar tejidos labrados.

Aunque algunas actividades textiles, como el hilado, pudieron estar ligadas al ámbito doméstico ${ }^{61}$, en al-Andalus el trabajo se organizó en talleres oficiales y talleres privados que permitieron atender las necesidades del príncipe, así como la gran demanda interna y el comercio exterior.

Los talleres textiles oficiales reciben el nombre de Dār al-Tirāz, institución adoptada por los musulmanes a partir de los obradores reales persas y los gineceos bizantinos $^{62}$. El Dār al-Tirāz trabajaba exclusivamente para el monarca, constituyéndose

las lanzaderas trabajan de orillo a orillo y para elevar los hilos que conforman la decoración se precisaba de un tirador que accionaba los lazos mientras el tejedor accionaba los pedales seleccionando el lazo para el curso de ligamento. En Tejidos. Vocabulario Técnico, Centre International d'Etude des Textiles Anciens (CIETA), Lyon, 1963 se define este tipo de telar como "creado para la confección de telas labradas. Los efectos del dibujo se consiguen por la tracción sobre las cuerdas del ramo en las cuales vienen relacionados los hilos de urdimbre por medio de arcadas y mallones... permiten la repetición automática de los efectos del dibujo en la anchura de la tela atando a cada cuerda del ramo las arcadas correspondientes a los distintos caminos... (y) la repetición automática de los efectos del dibujo a lo largo de la pieza por medio de anillas o lazos fijados en el ramo". S. SALADRIGAS CHENG, op.cit., 1996, p. 80, cita la fantástica descripción de un telar de estas características hecha por al-Nuwairi al narrar la visita del sultán mameluco al tiraz de Alejandría en 1376.

60 M. RETUERCE VELASCO “El templen $i^{1}{ }^{\text {er }}$ testimonio de telar horizontal en Europa?", Boletín de Arqueología Medieval, 1 (1987), pp. 71-77.

61 Aunque las labores de hilado debían estar concentradas en las zonas rurales, parece que para hilar se usaba un sistema que permitía el molinaje múltiple, que aunque no documentado en el caso andalusí es descrito por Ibn Miskawayh en el año 965 en la provincia de Azerbayán: citado en S. SALADRIGAS CHENG, op. cit., 1996, p. 78, nota 8 .

62 Tiraz es un término de origen persa que significa bordado. Por extensión se llamó tiraz a los talleres donde se hacían estos tejidos para uso exclusivo de los monarcas, por lo que solían instalarse en las dependencias del palacio. Posteriormente con la palabra tiraz se nombraron también los tejidos con inscripciones que reproducían versos del Corán, loas a Allah o frases elogiosas a los príncipes. De los tiraz salían los más bellos 
como un monopolio símbolo de la manifestación del poder, al igual que la institución de las cecas y otras manufacturas reales, como las de eboraria.

Se atribuye a 'Abd al-Rahmān II (822-852) la iniciativa de creación del tiraz cordobés, en el que ocupó el cargo de sāhib al-tirā $z^{63}$ Harith ibn Bazi, uno de los funcionarios más relevantes de la corte. El Dār al-Tirāz estaba instalado en Córdoba, pero otros talleres del tiraz se instalaron en otras ciudades de al-Andalus ${ }^{64}$, donde el príncipe podía realizar encargos.

Aunque nació como institución reservada para los monarcas, algunos gobernantes instalaron sus propios tiraz aprovechando épocas de debilidad, como ocurrió a finales del siglo IX cuando Ibn Hayayy, señor de Sevilla, instaló su taller particular de donde salían tejidos signados con su marchamo ${ }^{65}$.

La época califal fue la de mayor esplendor para estas manufacturas regias. De sus telares salían distintos tipos de tejidos y sus sedas competían con las procedentes de Bagdad y de Bizancio ${ }^{66}$. Estas telas se utilizaban por el califa y su familia pero una parte importante se destinaba como regalo para príncipes musulmanes y cristianos. Hay que tener en cuenta que al igual que otros objetos de lujo, la posesión de tejidos de seda era el reflejo de un estilo de vida opulento y refinado, por lo que los tejidos de seda constituían bienes delicados y muy valiosos mencionados en los documentos notariales, convirtiéndose en un excelente indicativo de rango social.

Del reinado de al-Hakam II nos han llegado importantes noticias sobre el tiraz cordobés a partir de las cuales se puede conocer su funcionamiento, entre las que destaca una visita que el califa realizó a este establecimiento, cuyos restos arqueológicos parecen haberse localizado en el arrabal de la capital, junto a la basílica de San Zoilo ${ }^{67}$. Pero durante el califato no funcionó únicamente la casa del tiraz de la capital, sino que se establecieron otros talleres que trabajaron en exclusiva para el califa en Sevilla, Almería, Málaga, Pechina, Fiñana y Baza ${ }^{68}$.

La importancia de la industria textil y la riqueza comercial que su producción generó para al-Andalus se debieron a los numerosos talleres textiles de carácter privado que funcionaron por su territorio. Posiblemente eran pequeños talleres agrupados en torno a un centro que los daba cohesión. Por lo que se desprende de las fuentes, las

tejidos de seda e hilos metálicos distinguidos con el marchamo real. En ellos estaban obligados a trabajar los artesanos más cualificados, aunque fuese contra su voluntad: M. T. HOUTSMA et alii (eds.), "Tiraz", Encyclopaedia of Islam, Leiden, 1936, vol. IV, pp. 785-793.

63 El sāhib al-tirāz, intendente al mando de la institución, era un funcionario con uno de los cargos más relevantes de la corte por la importancia que tuvo la producción de tejidos para satisfacer las necesidades de emires y califas. Se conocen varios de los nombres de estos funcionarios de la época califal: C. PARTEARROYO LACABA, "Estudio histórico-artístico de los tejidos de al-Andalus y afines", Bienes Culturales. Revista del Instituto del Patrimonio Histórico Español, 5 (2005), pp. 46-47.

64 R. B. SERJEANT, Islamic Textiles: Material for a History up the Mongol Conquest, Beirut, 1972, pp. 169-176.

65 J. VALLVÉ, op. cit., 1980, p. 226.

66 Ibídem, pp. 225-226, transcribe la descripción de Ibn Hawkal, viajero oriental que visitó al-Andalus en el año 998 a propósito de las variedades de tejidos que se producían en sus talleres.

67 A. ARJONA CASTRO y P. MARFIL RUIZ, "Posible localización de los restos arqueológicos del Dar al-Tiraz (Casa del tiráz) en la Córdoba musulmana", Boletín de la Real Academia de Córdoba de Ciencias, Bellas Letras y Nobles Artes, LXXXIII, 147 (2004), pp. 137-146.

68 L. SERRANO-PIEDECASAS FERNÁNDEZ, op. cit., 1986, p. 211. 
diferentes localidades se especializaron en la producción de un tipo determinado de tejido, ya fuera en lana, lino o seda ${ }^{69}$. Ya desde época califal se citan por la calidad de sus sedas los talleres de Sevilla, Zaragoza y, sobre todo, Almería, que en el siglo XII llegó a tener ochocientos telares donde se producían sedas que eran exportadas a todo el mundo ${ }^{70}$.

A partir del reinado de 'Abd al-Rahmān II la corte se orientalizó y empezaron a llegar objetos suntuarios procedentes de Bagdad. Este emir y sus descendientes gustaban de vestirse con ropas procedentes de los talleres bagdadíes y egipcios, cuyas decoraciones de influencia sasánida y de tradición copta ejercerían una influencia decisiva sobre las producciones andalusíes del período califal. A este respecto, cabe señalar que parte de la seda producida en al-Andalus se exportó a Egipto, donde sus condiciones climáticas más desfavorables para el cultivo de la morera no lo hacían posible $^{71}$ y a su vez Egipto influyó de manera decisiva en el desarrollo de la industria textil andalusí, porque fueron tejedores de esta procedencia, junto a tejedores sirios, los que aportaron una tecnología capaz de producir tejidos que competían en calidad y belleza con los de otras manufacturas orientales.

No se ha conservado ningún tejido de la época emiral, lo que nos impide caracterizar su producción. Los ejemplos más antiguos que se conservan se fechan en el siglo $\mathrm{X}$, aunque es necesario revisar las adscripciones y cronologías, porque se han establecido en base a criterios ornamentales y comparativos. Tampoco sabemos mucho de los talleres donde se realizaron, aunque las diferencias técnicas evidencian distintos obradores con distintas tradiciones textiles entre sus tejedores, y solo en casos concretos se pueden atribuir las piezas al Dār al-tirāz (tiraz de 'Abd al-Rahmān III, almaizar de Hisam II, izar de Colls).

Como ya hemos dicho, los tejidos más antiguos están realizados en tafetán con decoración en técnica de tapicería o bordado en seda ${ }^{72}$. El tejido hispanomusulmán más antiguo es una franja de tiraz de 'Abd al-Rahmān III (Museum of Fine Arts, Cleveland) con una inscripción muy perdida bordada en seda ${ }^{73}$. Sus similitudes con las

69 J. VALLVÉ, op. cit., 1980, p. 230.

70 M. V. LAGARDÈRE, op. cit., 1990, p. 99.

71 M. LOMBARD, op. cit., 1978, p. 94 cita también las importaciones a Egipto de seda de Siria y Sicilia.

72 Para el corpus de tejidos hispanomusulmanes y para las piezas que vamos a citar véanse: F. L. MAY, Silk Textiles of Spain: Eight to Fifteenth Century, Nueva York, 1957, una obra clásica para el estudio de los tejidos hispanos. En los últimos años son fundamentales los estudios de C. PARTEARROYO LACABA, entre los que citamos, además de los ya mencionados: "Los tejidos medievales en el Alto Aragón", Signos, Arte y Cultura en el Alto Aragón Medieval, Huesca, 1993; "Los tejidos de al-Andalus entre los siglos IX al XV (y su prolongación en el siglo XVI)", España y Portugal en las rutas de la seda. Diez siglos de producción y comercio entre Oriente y Occidente, Barcelona, 1996, pp. 58-73 y “Tejidos andalusíes”, Artigrama, 22 (2007), pp. 371-419. Véase también R. M. MARTÍN I ROS, “Tejidos”, Las Artes Decorativas en España, Colección Summa Artis, t. 45, vol. II, Madrid, 1999, pp. 9-80. Para los tejidos restaurados en el Instituto de Patrimonio Cultural de España a los que hacemos referencia en el texto vid. B. CULUBRET WORMS, "Catálogo de los tejidos hispanomusulmanes", Bienes Culturales. Revista del Instituto del Patrimonio Histórico Español, 5 (2005), pp. 147-160; y las obras estudiadas en J. DODDS (coord.), Al-Andalus. Las artes islámicas en España, cat. exp., Madrid, 1992.

73 Esta franja de tiraz de tafetán de lino con bordado en seda rosa ha sido publicada en España por C. PARTEARROYO LACABA, op. cit., 1997, pp. 368-370. El fragmento de Cleveland se completaba con otro desaparecido procedente del relicario de Santa Librada de la catedral de Sigüenza en cuya inscripción muy 
bandas de los califas fatimíes permiten establecer claras relaciones con los obradores egipcios ${ }^{74}$. Otra banda de tiraz atribuida a talleres andalusíes se conserva en el Musée de Cluny ${ }^{75}$.

De influencia egipcia con tradición en la producción copta se clasifica un grupo de tejidos con bandas decoradas en técnica de tapicería cuya cabeza de serie es el fragmento del almaizar de Hisam II (Real Academia de la Historia, Madrid), realizado en tafetán de seda con franjas de tapicería en seda e hilos metálicos. La central se decora con medallones que encierran animales y dos figuras, y en las franjas laterales corre una inscripción que ha servido para datarle entre los años 976 y $1013^{76}$. Estos tejidos, entre los que se encuentran también la franja de San Pedro de Montes (Instituto Valencia de Don Juan, Madrid) o el izar de Colls (Museo Arqueológico, Huesca), entre otros, muestran una influencia compositiva, ornamental y técnica con los tejidos egipcios de tradición copta ${ }^{77}$. Pero hay elementos diferenciadores que marcan la singularidad de estas obras. Es significativo el mayor empleo de hilos de seda y metálicos en las piezas hispanomusulmanas y las diferencias técnicas en la ejecución del punto de tapiz.

La franja del Pirineo (Instituto Valencia de Don Juan, Madrid) pudo formar parte de un tejido de ornamentación. Realizado íntegramente en técnica de tapiz con hilos de seda y metálicos, está formado por un medallón casi completo que encierra una

perdida se podía leer "En el nombre de dios el Misericordioso, el Compasivo. La bendición de Dios para su siervo Abd al-Rahma(n)", completada con la inscripción del fragmento del museo americano "(príncipe de los crey)entes al-Nasir li-Din al Muslimin, que Dios guarde. Esto fue hecho bajo la dirección de Durri, su siervo, en el año de 330 (941-942)".

74 Véanse como ejemplo los publicados en A. de MOOR, C. VERHECKEN-LAMNENS y A. VERHECKEN, op. cit., 2008, pp. 214-217. Estas bandas de tiraz se pusieron de moda en el mundo abbasí, siendo adoptados por los califas fatimíes y omeyas.

75 Citado por C. PARTEARROYO LACABA, op. cit., 2007, p. 380.

76 La inscripción dice "En nombre de Dios, el Clemente, el Misericordioso. Que la bendición divina, la prosperidad y la larga vida sean los atributos del imán, el siervo de Dios, Hisam, objeto de su benevolencia, el emir de los creyentes". El historiador al-Maqqarī dice del califa que "no dejó más insignia del califato que la oración en su nombre desde el al-mimbar y la inscripción de su nombre en las monedas y en las bandas del tiraz" (C. PARTEARROYO LACABA, op. cit., 2007, p. 378), lo que permitiría fechar el tejido en su reinado, aunque F. VALDÉS FERNÁNDEZ, "Algunas reflexiones sobre el estudio arqueológico de los tejidos de origen o procedencia andalusí”, M. MARÍN (ed.), Tejer y vestir, de la Antigüedad al Islam, Madrid, 2001, p. 385-387, plantea que dicho almaizar también pudo ejecutarse en Sevilla, donde se instaló el califa cuando abandonó Córdoba y ejerció un reinado ficticio (1034/5 a 1044-1060) protegido por el rey taifa Muhammad b. Ismail b. Abbad, quien adoptó los usos de los omeyas, entre los que estaba la institución del tiraz.

77 C. BERNIS, "Tapicería hispano-musulmana (siglos IX-XI)", Archivo Español de Arte, 27 (1954), pp. 189-211, estudia el corpus de tejidos hispanomusulmanes realizados en tapicería conocidos hasta el momento. En este artículo también analiza la técnica y considera que mantiene elementos en común con las manufacturas egipcias, como son las tramas oblicuas para adaptarse a los motivos, aunque también destaca algunas singularidades como tramas mucho más lasas que no siempre ocultan la urdimbre. Pero en los tejidos de tradición copta se emplean tramas curvas y la lanzadera volante para formar algunos elementos decorativos. Véase para el estudio técnico P. BORREGO DÍAZ, op. cit., 2005, pp. 75-76. El izar de Colls, descubierto en 1978 en esta iglesia del Pirineo oscense y fechado a comienzos del siglo XI, forma la decoración con tres franjas, la central con medallones florales y las laterales con la inscripción propia de los tiraz andalusíes y egipcios "En el nombre de Dios, el Clemente, el Misericordioso": L'Islam i Catalunya, cat. exp., Barcelona, 1998, pp. 74-78. 
hembra de pavo real ${ }^{78}$. Es una manufactura muy fina y delicada con una decoración que entronca con modelos orientales, si es que no es de esta procedencia. Si su origen es andalusí, permite establecer otro grupo de tejidos de factura más apretada que crea una superficie más lisa y que se caracterizan por los motivos de tradición persa, como animales pasantes o afrontados al árbol de la vida y motivos vegetales estilizados, diseños presentes en otros tejidos de este grupo como la guarnición de los hombros del alba del abad Biure (Museu Diocesà, Barcelona), entre otros ${ }^{79}$. Parece probable que estos tejidos fueran realizados en talleres con artesanos de origen sirio que introdujeron ese gusto por lo oriental tan patente en la estética andalusí desde tiempos de 'Abd al-Rahmān II.

El predominio de la técnica de tapiz en la época califal está en relación con su difusión en la cuenca del Mediterráneo al menos desde el inicio de la era. No habría que descartar que las diferencias de ejecución estuvieran en relación con la tradición de los tejedores en función de su origen, hispano o foráneo de ascendencia egipcia o siria, o bien en el tipo de telar utilizado, vertical u horizontal con pedales. Por otra parte, hay que señalar que en los tejidos andalusíes, a diferencia de los manufacturados en talleres egipcios con los que se han relacionado, la seda y los hilos metálicos se utilizan con más profusión, de modo que la seda se emplea a menudo en todo el tejido, mientras en los talleres orientales se reserva para la formación de las bandas de tapicería. Es decir, que independientemente del origen y tradiciones de los tejedores, la producción textil andalusí se caracterizó por su singularidad técnica que la confiere naturaleza propia.

Si los tafetanes y tapicerías fueron las técnicas más características del siglo X, a partir del siglo XI convivieron con los samitos de seda, aunque no podemos descartar que en el tiraz califal se realizaran también estos tejidos caracterizados por su decoración basada en sistemas especulares con animales reales o fantásticos confrontados incluidos en círculos perlados, escenas cinegéticas, y todo el repertorio clásico de la ornamentación sasánida que se continuará utilizando en las manufacturas abbasíes, cuyas telas se imitaron en los talleres instalados por todos los territorios islámicos. Los samitos andalusíes se diferencian por su intenso colorido, dominando los fondos rojos y los motivos estilizados perfilados en tonos pajizos dispuestos en frisos o incluidos en círculos perlados. Entre el corpus de los conservados, clasificados a partir de los años centrales de la undécima centuria, podemos citar alguno de los custodiados en la Colegiata de San Isidoro de León, como el forro del arca de San Isidoro; el forro del relicario de San Millán (Monasterio de Agustinos Recoletos de Yuso, San Millán de la Cogolla) o el Palio de las Brujas (Museu Episcopal, Vic).

En época califal también se documenta la práctica del bordado en seda e hilos metálicos aplicados con la técnica del hilo tendido ${ }^{80}$. La yuba de Oña (Colegiata de

78 C PARTEARROYO, "Franja del Pirineo", El esplendor de los Omeyas cordobeses, cat. exp., Granada, 2001, vol. II, pp. 261-263.

79 C. BERNIS, op. cit., 1954, pp. 204-211. Ningún tejido de este grupo presenta la singularidad y belleza de la franja del Pirineo.

80 Técnica que consiste en disponer el hilo de oro sobre la superficie del tejido al que se sujeta mediante puntadas transversales de seda. 
Oña, Burgos), emparentada con piezas de marfil como la arqueta de Leyre (Museo de Navarra, Pamplona) o el bote de al-Mughira (Musée du Louvre, París), se ha clasificado en el siglo $\mathrm{X}^{81}$, aunque su cronología se ha cuestionado en base a criterios técnicos ${ }^{82}$. Se relaciona con este bordado el sudario de San Lázaro de Autun (Tesoro de la Catedral), realizado en talleres almerienses en 1007 para 'Abd al-Malik ${ }^{83}$ y la capa de Fermo (Catedral de Fermo, Italia), según su inscripción hecha en Almería en el año 510 de la Hégira (1116-1117) ${ }^{84}$.

Almería se convirtió en el centro textil más próspero en la época almorávide ${ }^{85}$. Allí se hicieron tejidos al estilo de los de Bagdad con la decoración contenida en círculos y ejecutados en una nueva técnica de origen oriental, el lampás, cuyas características $\mathrm{y}$ evolución en los talleres hispanos difiere de la de los talleres orientales ${ }^{86}$. A partir del siglo XIII la singularidad de los tejidos andalusíes afecta a su técnica y decoración ${ }^{87}$, proceso que continuará hasta el fin de esta industria. Es a partir de este período cuando se puede hablar de una producción textil verdaderamente original y menos dependiente de los modelos y tradiciones foráneos.

La producción andalusí compitió con la egipcia, la siria, la iraní y la bizantina, es por eso que es necesario partir del estudio de los centros textiles del Delta del Nilo, así como prestar atención a la renovación que se genera en la industria siria de los siglos VIII y IX, lo que posiblemente nos permitiría establecer una comparación y diferenciación de las manufacturas andalusíes, de las que todavía falta un catálogo de conjunto y donde los estudios de caracterización de materiales y técnicas junto al análisis y cotejo de las fuentes documentales pueden contribuir al conocimiento más profundo de esta industria.

81 M. CASAMAR y J. ZOZAYA, "Apuntes sobre la yuba funeraria de la Colegiata de Oña (Burgos)", Boletín de Arqueología Medieval, 5 (1991), pp. 39-60. Miriam Ali de Unzaga la clasifica, en época califal y considera que su función original fue un manto ceremonial del tipo khil'a tirazi: M. ALI DE UNZAGA, «Nuevos datos sobre el bordado de Oña: testigo ineludible de la historia, la política y la cultura entre al-Andalus y Castilla», R. SÁNCHEZ DOMINGO (coord.), Oña. Un milienio. Actas del Congreso Internacional sobre el monasterio de Oña (1011-2011), Fundación milenario San Salvador de Oña, 2012, pp. 662-573; «Crónica de una coexistencia bordada: la túnica de Oña» en Monacatus, catálogo de la exposición del monasterio de San Salvador de Oña-Burgos, Fundación las Edades del Hombre, Salamanca, 2012, pp. 100-102; «Embroidered Politics», 13th Symposiumof the Textile Society of America TSA, Washington, septiembre 2012, (en línea mayo 2013); y «Rethinking Andalusi Textiles. The Multiple Biographies of the Oña's Embrodery» M. ALI DE UNZAGA y A. SHALEM (ed.), The Chasuble of Thomas Becket in the Cathedral of Fermo, The Bruschettini Foundation, Génova, (en prensa).

82 A. CABRERA LAFUENTE, "Telas hispanomusulmanas: siglos X-XIII", J. I. DE LA IGLESIA (coord.), V semanas de estudios medievales: Nájera, 1 al 15 de agosto de 1994, Logroño, 1995, pp. 204-207.

83 E. BAER, "The Suaire de Saint-Lazare. An Early Datable Hispano-Islamic Embroidery", Oriental Art, XIII, 1 (1967), p. 1-14.

84 L. CIAMPINI, "La capa de Fermo: un bordado de al-Andalus", A. FERNÁNDEZ PUERTAS y P. MARINETTO (coord.), Arte y cultura: patrimonio musulmán en Al-Andalus, Granada, 2009, pp. 143-178.

85 M. V. LAGARDËRE, op. cit., 1990, p. 99.

86 P. BORREGO DÍAZ, op. cit., 2005, pp. 78-80. La autora está estudiando su caracterización técnica en su tesis doctoral.

87 C. PARTEARROYO LACABA, “Tejidos almorávides y almohades”, Al-Andalus. Las artes islámicas en España, cat. exp., Madrid, 1992, pp. 105-113; Ídem, op. cit., 2007, pp. 383-402. 